\title{
Simple generation of site-directed point mutations in the Escherichia coli chromosome using Red ${ }^{\circledR} / \mathrm{ET}^{\circledR}{ }^{\circledR}$ Recombination Ralf Heermann*1, Tim Zeppenfeld ${ }^{2}$ and Kirsten Jung ${ }^{1}$
}

\author{
Address: ${ }^{1}$ Ludwig-Maximilians-Universität München, Department Biologie I, Bereich Mikrobiologie, Maria-Ward-Str. 1a, D-80638 München, \\ Germany and ${ }^{2}$ Gene Bridges GmbH, Im Neuenheimer Feld 584, 69120 Heidelberg, Germany \\ Email: Ralf Heermann* - heermann@Imu.de; Tim Zeppenfeld - tim.zeppenfeld@genebridges.com; Kirsten Jung - jung@lmu.de \\ * Corresponding author \\ Published: 24 April 2008 \\ Microbial Cell Factories 2008, 7:14 doi:10.1 186/1475-2859-7-14 \\ Received: 15 February 2008 \\ Accepted: 24 April 2008 \\ This article is available from: http://www.microbialcellfactories.com/content/7/1/14 \\ (c) 2008 Heermann et al; licensee BioMed Central Ltd. \\ This is an Open Access article distributed under the terms of the Creative Commons Attribution License (http://creativecommons.org/licenses/by/2.0), \\ which permits unrestricted use, distribution, and reproduction in any medium, provided the original work is properly cited.
}

\begin{abstract}
Background: Introducing point mutations into bacterial chromosomes is important for further progress in studies relying on functional genomics, systems- and synthetic biology, and for metabolic engineering. For many investigations, chromosomal systems are required rather than artificial plasmid based systems.
\end{abstract}

Results: Here we describe the introduction of a single point mutation into the Escherichia coli chromosome by site-directed mutagenesis without leaving any selection marker. We used $\operatorname{Red}^{\circledR /}$ ET ${ }^{\circledR}$ Recombination in combination with $r p s L$ counter-selection to introduce a single point mutation into the E. coli MGI 655 genome, one of the widely used bacterial model strains in systems biology. The method we present is rapid and highly efficient. Since single-stranded synthetic oligonucleotides can be used for recombination, any chromosomal modification can be designed.

Conclusion: Chromosomal modifications performed by $r p s L$ counter-selection may also be used for other bacteria that contain an $r p s L$ homologue, since $\operatorname{Red}^{\circledR} / E T^{\circledR}$ Recombination has been applied to several enteric bacteria before.

\section{Background}

$\operatorname{Red}^{\circledast} / \mathrm{ET}^{\circledast}$ Recombination is a powerful tool for the chromosomal inactivation of genes or complete operons [1-3]. This method is based on the homologous in vivo replacement of a gene/operon of any size and chosen position with a resistance cassette (e.g. a gene conferring antibiotic resistance) in a precise and specific manner by the $\lambda$-phage $\operatorname{Red} \gamma \beta \alpha$ recombination system and is applicable to all enteric bacteria. For certain purposes, the introduction of single point mutations is required rather than complete gene replacement or deletion, e.g. to modify a promoter or specifically inactivate the catalytic center of a certain gene product. In most cases, positive phenotypic selection for the introduced mutation is un-achievable, so that mutagenesis must be coupled to a counter-selection approach. A powerful counter-selection system based on the $r p s L$ gene ( $r p s L$-neo) and streptomycin selection for the introduction of point mutations into Bacterial Artificial Chromosomes (BACs) has been described [4], and this method was further useful for the recombination of large DNA-fragments into BACs [5]. This counter-selection system is based on the rpsL gene encoding the $S 12$ ribosomal protein, which is the target of streptomycin. Chromosomal mutations within $r p s L$ are responsible for streptomycin resistance [6]. Many E. coli strains commonly used for protein overproduction and/or metabolic engineering, including MC4100 [7], JM110 [8], Rosetta DE3 (Novagen, Darmstadt), HB101 (ATCC 33694), and 
TOP10 (Invitrogen, Karlsruhe) carry an altered $r p s L$ gene conferring streptomycin resistance. The counter-selection system takes advantage of the fact that mutations within $r p s L$ leading to streptomycin resistance are recessive in a merodiploid strain.

Here we describe a rapid method for site-directed mutagenesis of the E. coli chromosome. We used rpsL counterselection in combination with $\operatorname{Red}^{\circledast} / \mathrm{ET}^{\circledast}$ Recombination to introduce a single point mutation into the $k d p A$ gene locus of the MG1655 strain genome. We show that rpsL counter-selection is applicable for introducing modifications into the bacterial chromosome. Single-stranded synthetic oligonucleotides can be used for recombination, so any chromosomal modification can be designed.

\section{Results}

Introduction of a single point mutation into $k d p A$ was chosen to demonstrate rpsL based counter-selection in combination with $\operatorname{Red}^{\circledast} / \mathrm{ET}^{\circledast}$ Recombination on the E. coli chromosome. KdpA is the $\mathrm{K}^{+}$-translocating subunit of the KdpFABC system, a high affinity $\mathrm{K}^{+}$uptake system in $E$. coli, which is essential for growth under $\mathrm{K}^{+}$-limitation [9]. Previously, clones obtained by random mutagenesis were screened for their inability to grow under $\mathrm{K}^{+}$-limiting conditions. The mutation in one of these clones (E. coli TK2204) was mapped to $k d p A$, and was designated $k d p A 4$ [10]. Detailed analysis of $k d p A 4$ revealed a point mutation at position 1033 ( $\mathrm{G}$ to $A$ ). This substitution changes glycine 345 to serine. Glycine 345 is located within the $\mathrm{K}^{+}$ selectivity filter of subunit KdpA [11], and the substitution prevents growth under $\mathrm{K}^{+}$-limiting conditions. Since $E$. coli strain TK2240 is not isogenic to E. coli MG1655 (Tab. 1 ), and the latter strain was already used for systems biological studies of the Kdp system [12], we aimed to introduce the original $k d p A 4$ point mutation into the E. coli MG1655 chromosome. As $k d p A 4$ prevents growth under $\mathrm{K}^{+}$-limitation, no positive selection for the mutants was possible. Thus, we applied the rpsL based counter-selection method to screen for mutants.

In contrast to other K-12 E. coli strains (see Introduction), strain MG1655 contains the wild-type $r p s L$ gene and is naturally sensitive to streptomycin. Therefore, an altered $r p s L$ gene conferring streptomycin resistance was introduced first. For this purpose rpsL150 of E. coli MC4100 was amplified and recombined into E. coli MG1655 carrying plasmid pRed/ET(amp). The temperature sensitive (ts) origin of replication of plasmid pRed/ET(amp) restricts replication at $37^{\circ} \mathrm{C}$. After each recombination step cells were incubated at $37^{\circ} \mathrm{C}$ to remove the plasmid, and the colonies obtained were tested for plasmid loss.

In general, it is not absolutely necessary to cure strains from plasmid pRed/ET(amp) after each recombination step. Since araBAD promoter activity is not completely down-regulated in the absence of arabinose, the occurrence of any rearrangement was prevented. Resistant colonies were not obtained on the control plate (cells equally treated without $\operatorname{Red}^{\circledast} / \mathrm{ET}^{\circledast}$ production). The overall recombination frequency was about $4 \times 10^{-8} / \mu \mathrm{g}$ DNA. All clones obtained were streptomycin resistant and ampicillin sensitive. The efficiency of proper recombination was $100 \%$ (i.e. no false-positives). We observed no differences between E. coli MG1655 and E. coli MG1655 rpsL150, neither in growth nor in $k d p F A B C$ transcription/KdpFABC translation fidelity (data not shown).

The general mechanism of $r p s L$ counter-selection is illustrated in Fig. 1. A prerequisite for the strain to be used is a chromosomal encoded resistance to streptomycin conferred by a mutation in $r p s L$, which implies that this method can only be applied to bacterial stains with an rpsL homologue. Briefly, cells carrying a mutated chromosomal rpsL gene (e.g. rpsL150), exhibiting streptomycin resistance, are modified by the introduction of linear DNA comprising the rpsL-neo cassette with 50 bp homology arms surrounding the target gene site of interest. The additional wild-type allele of $r p s L$ provided by the $r p s L$-neo cassette is dominant over rpsL150, and cells become sensitive to streptomycin and resistant to kanamycin, when the cassette has been inserted into the chromosome. In the next step, a DNA-fragment carrying the mutated site in the target gene (e.g. $k d p A)$ is introduced into cells, which recombines and replaces the $r p s L$-neo cassette. Due to the loss of the rpsL wild-type allele, recombinants regain streptomycin resistance again and can easily be selected. Furthermore, recombinants become kanamycin sensitive

Table I: E. coli strains used and their genotypes

\begin{tabular}{|c|c|c|}
\hline E. coli strain & Genotype & Reference \\
\hline MGI655 & wild-type; F- lambda-ilvG rfb50 rphl & {$[31]$} \\
\hline MC4I00 & F- araDI $39 \Delta$ (argF-lac) U169 rpsLI50 relAI flb-530I fruA25 deoCl ptsF25 & [7] \\
\hline TK2204 & F- thi rha lacZ(am) nagA kdpA4 trkA405 trkDI & {$[10]$} \\
\hline MGI655 rpsLI50 & F- lambda- ilvG rfb50 rphI rpsLI50 (StrR) & this work \\
\hline MGI655 rpsLI50 kdpA4:rpsL-neo & F- lambda- ilvG rfb50 rphI rpsLI50 kdpA::rpsL-neo (Kan $\left.{ }^{R}, \mathrm{Str}^{\mathrm{S}}\right)$ & this work \\
\hline MGI 655 rpsLI 50 kdpA4 & F- lambda-ilvG rfb50 rphI rpsLI $50\left(\mathrm{Str}^{\mathrm{R}}\right) \mathrm{kdpA4}$ & this work \\
\hline
\end{tabular}




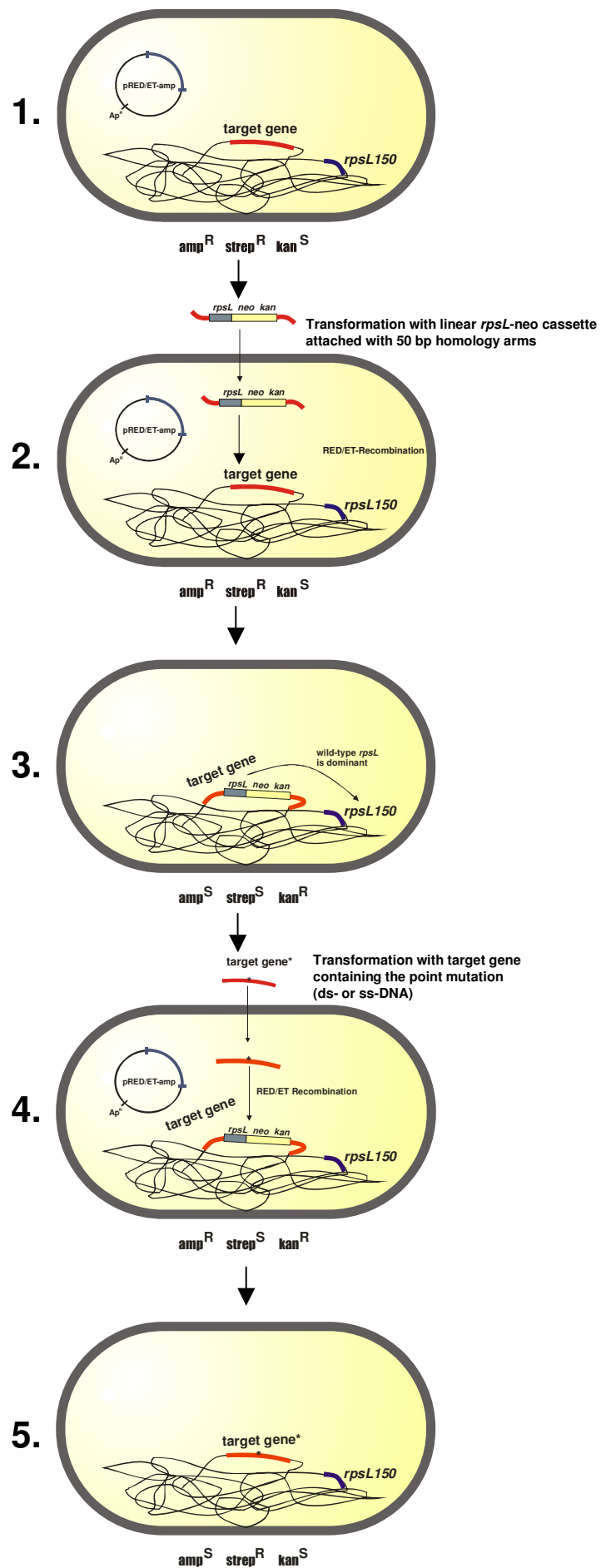

Figure I

Basic principle of introducing mutations into the bacterial chromosome using rpsL-based counter-selection. Prerequisite for the used strain is a chromosomal resistance against streptomycin conferred by a mutation in rpsL. If necessary, the strain can be made Stre $p^{R}$ before by homologous recombination of a mutated rpsL gene (e.g. rpsL I 50) (step I). Around the point of interest within the target gene, the rpsL-neo cassette is inserted via 50 bp homology arms by Red ${ }^{\circledR} / E^{\circledR}{ }^{\circledR}$ Recombination (step 2). Positive clones are Kan ${ }^{R}$. Due to the additional wild-type allele of $r p s L$, the strain becomes Strep ${ }^{S}$ (step 3). In the next step, the rpsL-neo cassette is replaced by Red ${ }^{\circledR} /{ }^{-}{ }^{\circledR}$ Recombination against the modified double-stranded (ds) or single-stranded (ss) DNA-fragment of the target gene (carrying the point mutation) (step 4). Positive clones become Strep ${ }^{R}$ again and can therefore easily be selected (step 5 ). The asterisk represents the point mutation within the target gene. 
due to the loss of the rpsL-neo cassette. Selection for streptomycin resistant clones is carried out on complex medium agar plates, so clones grow within 1-2 days of incubation. Within this short incubation time, clones with spontaneous $r p s L$ mutations rarely appear.

Insertion of the $k d p A G 1033 A$ point mutation into the chromosome is illustrated in Fig. 2. The homology arms of the rpsL-neo cassette were constructed in a way that a 50 bp homology to $k d p A$ was ensured on each side of the point mutation, while the downstream homology arm contained the point mutation. The PCR product $k d p A 4-$ rpsL-neo (1.4 kb) was recombined into E. coli MG1655 rpsL150 carrying plasmid pRed/ET(amp). About half of the colonies obtained represented false positives based on the number of colonies observed on the control plates. Plasmid loss appeared to be a strain MG1655 specific problem, because other E. coli strains (e.g. HB101, W3110, DH5a, DH10B) generally exhibit $>90 \%$ validated positives. Nevertheless, the overall recombination frequency for the $k d p A 4-r p s L$-neo cassette in E. coli MG1655 was about $3 \times 10^{-7} / \mu \mathrm{g}$ DNA ( $25 \%$ of clones were correct), which was checked by testing for sensitivity to streptomycin $\left(\right.$ Strep $\left.^{\mathrm{S}}\right)$ and ampicillin $\left(\mathrm{Amp}^{\mathrm{S}}\right)$, and resistance to kanamycin $\left(\operatorname{Kan}^{\mathrm{R}}\right)$. Introduction of the $k d p A 4-r p s L-n e o$ cassette was verified for two Strep ${ }^{S}$, Kan ${ }^{R}$ and Amp ${ }^{S}$ clones by PCR analysis using counterA4_sense and counter_A4 antisense primers. For both clones, a fragment of $1.44 \mathrm{~kb}$ was obtained, which corresponded to the inserted $k d p A 4$ rpsL-neo cassette (Fig. 2, Fig. 3a).

Next, the $k d p A 4-r p s L$-neo cassette was replaced by a DNAfragment containing the $k d p A 4$ mutation, which was obtained by PCR using an E. coli TK2204 chromosomal DNA template. The DNA-fragment was recombined into E. coli MG1655 rpsL150 kdpA4:rpsL-neo carrying plasmid pRed/ET(amp). Depending on the amount of cells plated, limited background growth was visible as a kind of smear at this step. Nevertheless, single colonies were clearly visible. Several hundred clones were obtained, and about half of the number of clones observed on the recombination plate was observed on the control plate. The overall Strep ${ }^{\mathrm{R}}, \mathrm{Kan}^{\mathrm{S}}$ and $\mathrm{Amp}^{\mathrm{S}}$ clone yield was about $10 \%$, indicating that the recombination frequency was about $2 \times 10^{-}$ $7 / \mu \mathrm{g}$ DNA. The replacement of the $k d p A 4-r p s L$-neo cassette against the mutated $k d p A$ gene fragment ( $k d p A 4)$ was tested for two clones which were Strep ${ }^{\mathrm{R}}, \operatorname{Kan}^{\mathrm{S}}$ and $A m p^{S}$ by PCR analysis. As expected, the size of the PCR products was about 150 bp confirming the loss of the $k d p A 4-r p s L$ neo cassette (Figs. 2 and 3a).

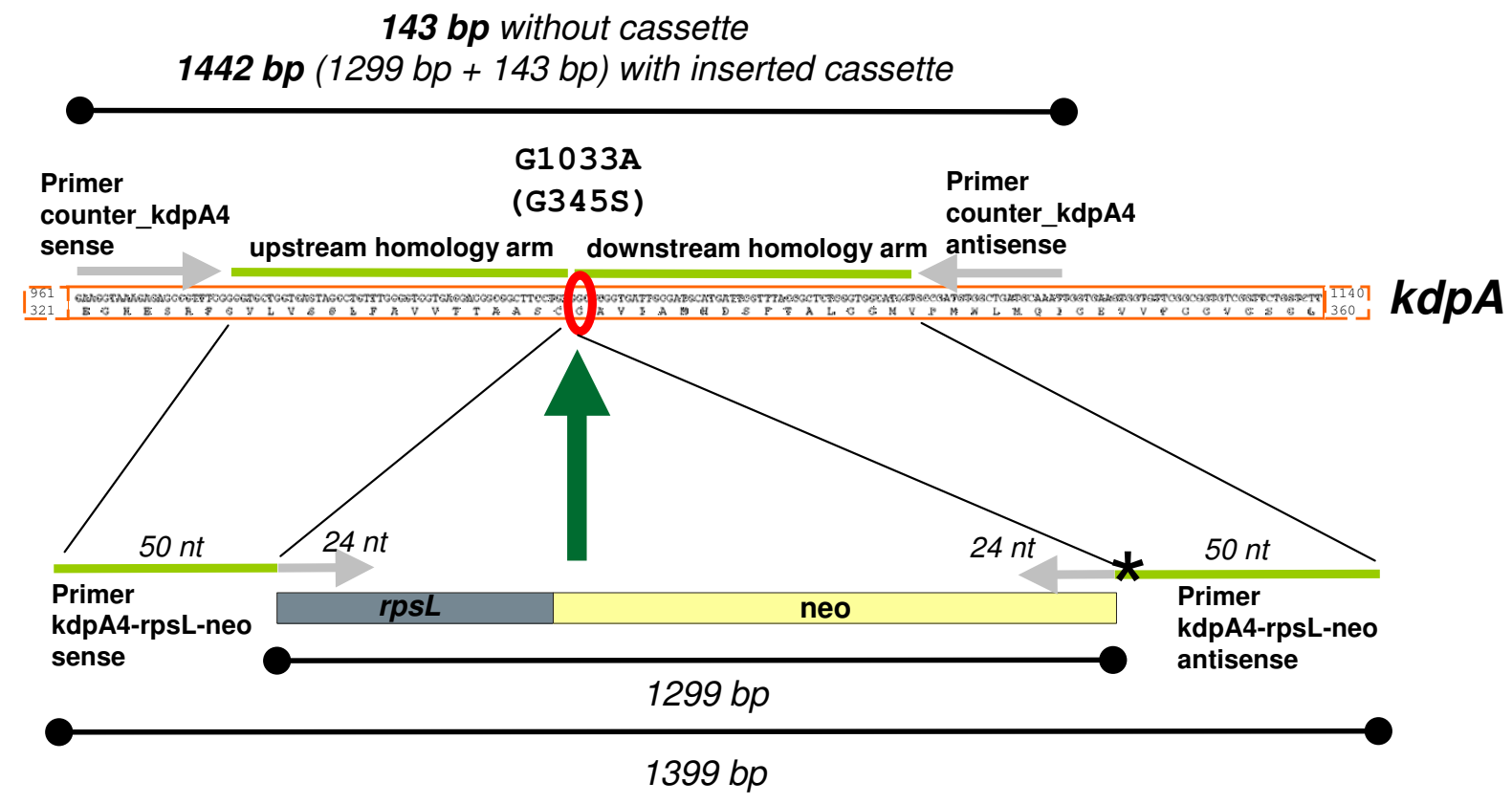

\section{Figure 2}

Primer design to introduce the replacement G 1033 to A in kdpA encoding KdpA/G345S. The homologous parts of the homology arms to $k d p A$ are indicated as well as the primers for introduction and verification of the $r p s L-n e o$ cassette inserted into the $k d p A$ gene. In the lower part, the composition and the sizes of the linear DNA-fragments for recombination are indicated. The asterisk represents the mutated base in $k d p A$. In the upper part, the sizes of DNA-fragments confirming the introduction or loss of the $r p s L-n e o$ cassette are indicated. $\mathrm{nt}=$ nucleotides. 


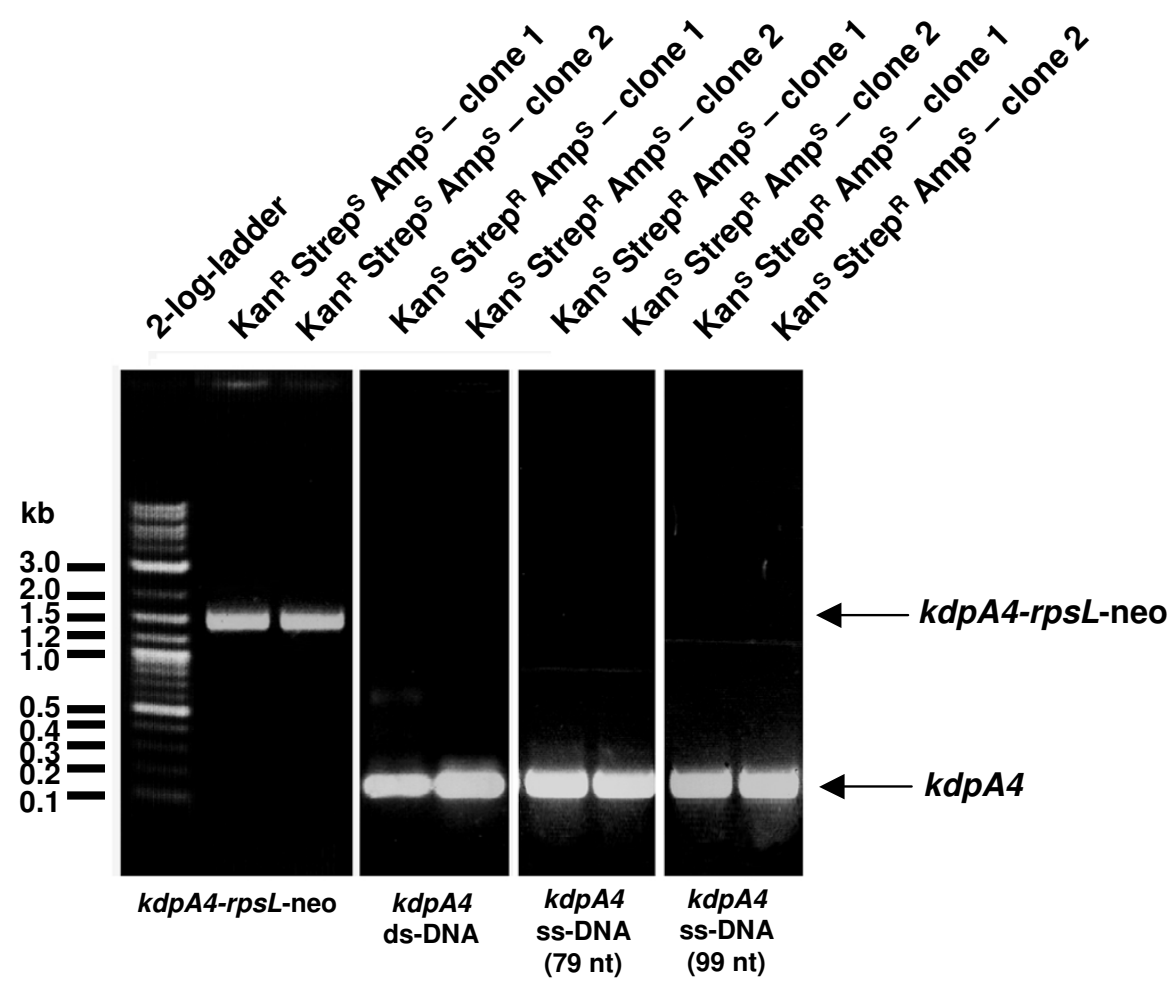

A

E. coli MG1655

E. coli MG1655 rpsL150 kdpA4
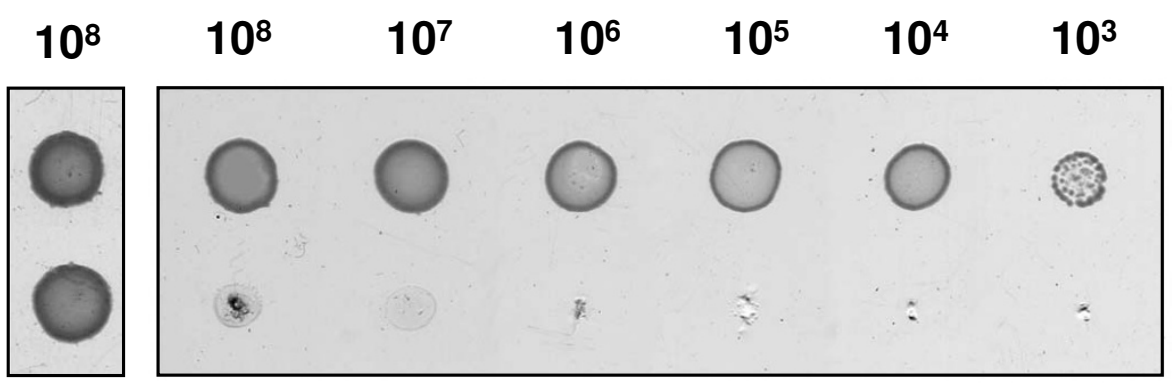

$10 \mathrm{mM} \mathrm{K}^{+}$

$0.02 \mathrm{mM} \mathrm{K}^{+}$

B

Figure 3

Verification of the insertion/replacement of the rpsL-neo cassette in $k d p A$ by PCR (A) and verification of the kdpA4 phenotype (growth deficiency under $\mathbf{K}^{+}$-limitation) (B). A Two positive clones of each recombination step were analyzed by colony PCR. On the left panel, insertion of the rpsL-neo cassette into kdpA was verified, on the two middle and the right panel the replacement of the kdpA4-rpsL-neo cassette by the double-stranded and the two single-stranded kdpA4fragments ( $k d p A$ containing the point mutation GI033A) was confirmed. Below the gels pictures, the respective DNA-fragment used for the recombination is indicated. $\mathrm{ds}=$ double-stranded, $\mathrm{ss}=$ single-stranded, $\mathrm{nt}=$ nucleotides. $\mathrm{B}$ Cells were grown overnight in minimal medium containing $10 \mathrm{mM} \mathrm{K}$, washed three times in minimal medium containing $0.02 \mathrm{mM} \mathrm{K}$, diluted, and $2 \mu \mathrm{l}$ of each suspension containing the indicated number of cells was spotted onto a minimal medium agar plate containing $0.02 \mathrm{mM}$ $\mathrm{K}^{+}$or $10 \mathrm{mM} \mathrm{K}^{+}$, respectively. Cells were incubated overnight at $37^{\circ} \mathrm{C}$ 
In principle, this method should work for engineering a mutation into the chromosome using single-stranded synthetic oligonucleotides. To test this, two oligonucleotides were used for recombination, one 79 nucleotides (nt) and one $99 \mathrm{nt}$ in length, consisting of $39 \mathrm{nt}$ and $49 \mathrm{nt}$ length homology arms, respectively, surrounding the point mutation. The recombination frequency for both oligonucleotides was observed to be about $2 \times 10^{-7} / \mu \mathrm{g}$ DNA, comparable to that observed for double-stranded DNA. Replacement of the kdpA4-rpsL-neo cassette against the mutated $k d p A$ gene fragment ( $k d p A 4)$ was confirmed for two Strep ${ }^{R}$, Kan ${ }^{S}$ and $A m p^{S}$ clones from each recombination setup (79 nt and 99 nt oligo) by PCR analysis (Figs. 2 and $3 a)$.

DNA sequencing confirmed the accurate homologous recombination of the fragments within the $k d p A$ gene, and introduction of the G1033A mutation. Furthermore, strain MG1655 with the point mutation in $k d p A$ was tested phenotypically for growth under $\mathrm{K}^{+}$-limitation. As shown in Fig. 3b, cells with a kdpA4 mutation exhibit growth defects under $\mathrm{K}^{+}-$limiting conditions $(0.02 \mathrm{mM}$ $\mathrm{K}^{+}$).

\section{Discussion}

New approaches to introduce point mutations into bacterial chromosomes are important for advancing functional genomics and systems biology investigations as well as for metabolic engineering. In this way, mutations are introduced and copy numbers of the encoded proteins are retained. Moreover, it is important to avoid polar effects from remaining antibiotic resistance cassettes in the gene of interest.

Here we demonstrated that $r p s L$ counter-selection in combination with $\operatorname{Red}^{\circledast} /$ ET $^{\circledast}$ Recombination is an efficient approach to modify the E. coli chromosome. We introduced a single point mutation into the $k d p A$ locus of $E$. coli MG1655, one of the bacterial model strains used widely in systems biological approaches. The method described here is convenient because a selectable marker is used in each step. Furthermore, there is no need for cloning the gene fragment into a special vector, which makes the method time efficient. Recombination between the two $r p s L$ alleles is improbable, because $\operatorname{Red}^{\circledast} / \mathrm{ET}^{\circledast}$ Recombination starts recombination at the ends of a linear fragment (Y. Zhang, personal communication), and the wild-type rpsL allele located on the linear PCR-fragment is flanked by about 300 bp 50 of which are responsible for precise recombination. The method that we present works with synthetic oligonucleotides as well. Thus it might also be used for the replacement of multiple nucleotides, for deletions or insertions within the gene of interest.
Other counter-selection methods have been described. The introduction of a single point mutation into the E. coli chromosome (at the galK locus), has been described using $\lambda$ prophage suicide counter-selection [13]. thyA- and galKbased counter-selection systems have been successfully applied to the modification of BACs $[14,15]$, and these methods allow modification of DNA without leaving a selectable marker at the modification site likewise rpsLbased counter-selection. While the rpsL marker gene is only slightly modified, these methods require complete deletion of the respective marker gene. Furthermore, in the case of rpsL counter-selection, cells can be grown in complex medium instead of in minimal medium, which speeds up the process and circumvents spontaneous mutations.

Another counter-selection method is recA- dependent, which relies on the integration and resolution of a special shuttle vector, and has been successfully applied to modify BACs $[16,17]$. This method requires time-consuming restriction and ligation steps. These same time-consuming steps are necessary for the "gene gorging" method described previously [18], and most of the other counterselection systems which use recognition sites for rare-cutting restriction endonucleases, like I-SceI. Nevertheless, these methods were successfully utilized for the modification of BACs, and the E. coli genome $[19,20]$. Recently, counter-selection using I-SceI rare restriction sites has been applied to modify the Salmonella enteritidis genome using PCR-based recombination cassettes, thereby overcoming the disadvantages described above [21]. Another common, simple method is sacB-based counter-selection [22], but this method implies a high frequency of spontaneous point mutations in the selection marker $s a c B$, which significantly increases the background after negative selection [15]. Likewise, spontaneous point mutations within the rpsL-neo cassette might also promote the occurrence of false-positive clones. Such false-positive clones can easily be identified by checking for streptomycin sensitivity after recombination of the r $p s L$-neo cassette.

\section{Conclusion}

We present an efficient and non-disruptive approach to introduce point mutations into the E. coli chromosome. Chromosomal modifications performed by rpsL counterselection may also be used for enteric bacteria that contain an $r p s L$ homologue and in which $\operatorname{Red}^{\oplus} / \mathrm{ET}^{\circledast}$ Recombination is functional. $\operatorname{Red}^{\circledast} / \mathrm{ET}^{\circledast}$ Recombination or analogous methods have been efficiently applied in Salmonella [23], Yersinia [24], Shigella [25], Citrobacter [26], and Serratia [27] species, and all of these species have a rpsL homologue. The versatility of this system illustrates its potential for furthering studies in an important clade of organisms. 


\section{Materials and methods Plasmids and Strains}

E. coli strains are listed in Tab. 1. Plasmid pRed/ET(amp) was obtained from the "Quick and Easy E. coli Gene Deletion Kit" (Gene Bridges, Heidelberg), and the rpsL-neo template DNA was obtained from the "Counter-Selection BAC Modification Kit" (Gene Bridges, Heidelberg). All oligonucleotides were obtained from Operon $\mathrm{GmbH}$ (Köln) in a salt-free grade.

\section{Media and Growth Conditions}

Cells were grown in LB broth [28] under aerobic conditions at the designated temperature. For solid media, $1.5 \%(\mathrm{w} / \mathrm{v})$ agar was added. Antibiotics were used at the following final concentrations: ampicillin $(50 \mu \mathrm{g} / \mathrm{ml})$, carbenicillin $(50 \mu \mathrm{g} / \mathrm{ml}$ in solid media), kanamycin (15 $\mu \mathrm{g} / \mathrm{ml})$, streptomycin $(50 \mu \mathrm{g} / \mathrm{ml})$, and tetracycline $(3 \mu \mathrm{g} /$ $\mathrm{ml}$ ). For verification of the $\mathrm{K}^{+}$-dependent growth deficient phenotype, a phosphate buffered minimal medium was used containing variable amounts of $\mathrm{K}^{+}(0.02 \mathrm{mM}$ and 10 $\mathrm{mM}$, respectively) [29].

\section{Competent cells and transformation}

Transformations of cells by introduction of linear DNAfragments for recombination were performed by electroporation according to the protocol recommended by the technical manual of the "Quick and Easy E. coli Gene Deletion Kit" (Gene Bridges, Heidelberg). Briefly, two 1.4 $\mathrm{ml}$ cultures of the designated strain were cultivated in 2.0 $\mathrm{ml}$ LidBac tubes (Eppendorf, Hamburg) in a thermomixer at $30^{\circ} \mathrm{C}$. At an absorbance of $0.3(600 \mathrm{~nm})$, freshly prepared L-arabinose was added $(0.35 \% \mathrm{w} / \mathrm{v}$, final concentration) to one of the cultures inducing red $\gamma \beta \alpha /$ recA expression, and expression was continued at $37^{\circ} \mathrm{C}$. A control culture with no arabinose was incubated as a control. After $45 \mathrm{~min}$, cells were harvested by centrifugation, washed twice with $10 \%(\mathrm{v} / \mathrm{v})$ ice cold glycerol, and resuspended in a final volume of $30 \mu \mathrm{l}$ in $10 \%(\mathrm{v} / \mathrm{v})$ ice cold glycerol. DNA-fragments (400-600 ng ds-DNA, 150 ng ssDNA) were then added to both samples, and mixtures were incubated on ice for $2 \mathrm{~min}$. Subsequently, samples were transferred to electroporation cuvettes (BioRad, München), and electroporation was carried out with a MicroPulser (BioRad, München) at constant $2.5 \mathrm{kV}$ for 5 ms (Ec2 program). Cells were immediately removed from the cuvettes by mixing with $1 \mathrm{ml} \mathrm{LB}$ medium, and then incubated at $37^{\circ} \mathrm{C}$ for $3 \mathrm{~h}$. Cells were collected by centrifugation, and all cells ( $\left.\sim 10^{9}\right)$ were plated on LB agar containing the appropriate antibiotics.

Transformations of cells by introduction of plasmids were performed with chemically $(\mathrm{RbCl})$ competent cells as described elsewhere [30].

\section{In vitro amplification of DNA-fragments}

Linear DNA-fragments comprising either the wild-type or mutated $r p s L$ gene (rpsL150) were obtained by polymerase chain reaction using primers rpsL_up1 (5'-CTTGACACCTTTTCGGCATCGC-3') and rpsL_down1 (5'-CGTTGTTAATTCAGGATTGTCC-3') with genomic DNA from $E$. coli MG1655 or MC4100, respectively, as templates. The $k d p A 4-r p s L$-neo cassette was amplified using primers with homology arms consisting of 50 nucleotides upstream and downstream of the targeted point mutation and 24 nucleotides homologous to the rpsL-neo cassette (kdpA4rpsL-neo sense 5'GCGTGCTGGTCAGTAGCCTGTTTGCGGTCGTGACGAC GGCGGCTTCCTGTGGCCTGGTGATGATGGCG-

GGATCG-3'; kdpA4-rpsL-neo antisense 5'ACCATGCCACCGAGAGCGGTAAACGAATCATGCATCG CAATCACCGCGCTTCAGAAGAACTCGTCAAGAAG-

GCG-3') using the rpsL-neo template DNA (Gene Bridges, Heidelberg). For amplification of the mutated $k d p A$ gene $(k d p A 4)$, primers that bind upstream and downstream, respectively, of the homology arms were used (counter_kdpA4_sense 5'-AGGTAAAGAGAGCCGTTTCGG-3', and counter_kdpA4_antisense 5'-ATTTGCATCAGCCACATCGGC-3'), and the DNA-fragment was obtained by PCR using genomic DNA of E. coli TK2204 as template. For further verification of the point mutation in $k d p A$, the targeted portion of the $k d p A$ gene was amplified with primers kdpA2_sense (5'-CCAACGGCGCTGTGCTTTGCC-3') and kdpA2_antisense (5'-GAATAGCGCCAGTTGTTTACG-3'). For all amplifications Phusion $^{\mathrm{TM}}$ polymerase (New England Biolabs, Frankfurt) was used, and the protocol recommended for this polymerase was applied ( 30 cycles, $10 \mathrm{sec} 98^{\circ} \mathrm{C}, 20 \mathrm{sec}$ $50^{\circ} \mathrm{C}, 15-30 \mathrm{sec} 72^{\circ} \mathrm{C}$ ). For large amounts of DNA, each PCR was performed in parallel several times. PCR products were separated by agarose gel electrophoresis, and DNA was isolated and concentrated by elution in a final volume of $10 \mu \mathrm{l}$ using the MinElute Gel Extraction Kit (Qiagen, Hilden). For replacement of the $k d p A 4-r p s L-n e o$ cassette by single-stranded oligonucleotides, we used oligonucleotides kdpA4_80_cassette (5'GTAGCCTGTTTGCGGTCGTGACGACGGCGGCTTCCTG TAGCGCGGTGATTGCGATGCATGATTCGTTTAC-

CGCTCTCGG-3') and kdpA4_100_cassette (5'GTGCTGGTCAGTAGCCTGTTTGCGGTCGTGACGACGG CGGCTTCCTGTAGCGCGGTGATTGCGATGCATGAT-

TCGTTTACCGCTCTCGGTGGCATGGTG-3') harboring the $k d p A 4$ mutation. For verification of correct clones, colony PCR was performed.

\section{Abbreviations}

BAC: Bacterial Artificial Chromosome; nt: nucleotides; ds: double-stranded; ss: single-stranded. 


\section{Authors' contributions}

RH has performed the experiments and drafted the manuscript. TZ contributed ideas for performing the experiments, professional support, and helpful suggestions for improving the manuscript. $\mathrm{KJ}$ is the project leader and has improved the manuscript. All authors have read and approved the final manuscript.

\section{Acknowledgements}

We thank Sonja Kroll for excellent technical assistance. This work was financially supported by the Deutsche Forschungsgemeinschaft (Excl I4/I), and the BMBF (SysMO, project 4).

\section{References}

I. Zhang Y, Buchholz F, Muyrers JP, Stewart AF: A new logic for DNA engineering using recombination in Escherichia coli. Nat Genet 1998, 20:123-128.

2. Datsenko KA, Wanner BL: One-step inactivation of chromosomal genes in Escherichia coli K-I 2 using PCR products. Proc Natl Acad Sci USA 2000, 97:6640-6645.

3. Wang J, Sarov M, Rientjes J, Fu J, Hollak H, Kranz H, Xie W, Stewart AF, Zhang Y: An improved recombineering approach by adding RecA to lambda Red recombination. Mol Biotechnol 2006, 32:43-53.

4. Zhang Y, Muyrers JP, Rientjes J, Stewart AF: Phage annealing proteins promote oligonucleotide-directed mutagenesis in Escherichia coli and mouse ES cells. BMC Mol Biol 2003, 4:I

5. Rivero-Muller A, Lajic S, Huhtaniemi I: Assisted large fragment insertion by Red/ET-recombination (ALFIRE)-an alternative and enhanced method for large fragment recombineering. Nucleic Acids Res 2007, 35:e78.

6. Gill $A E$, Amyes SG: The contribution of a novel ribosomal SI2 mutation to aminoglycoside resistance of Escherichia coli mutants. J Chemother 2004, 16:347-349.

7. Casadaban MJ: Transposition and fusion of the lac genes to selected promoters in Escherichia coli using bacteriophage lambda and Mu. J Mol Biol 1976, 104:54I-555.

8. Yanisch-Perron C, Vieira J, Messing J: Improved MI3 phage cloning vectors and host strains: nucleotide sequences of the MI3mpI8 and pUCI 9 vectors. Gene 1985, 33:103-119.

9. Epstein $\mathrm{W}$ : The roles and regulation of potassium in bacteria. Prog Nucleic Acid Res Mol Biol 2003, 75(293-320):293-320.

10. Epstein W, Davies M: Potassium-dependant mutants of Escherichia coli K-12. J Bacteriol 1970, I 01:836-843.

II. Durell SR, Bakker EP, Guy HR: Does the KdpA subunit from the high affinity $\mathrm{K}^{+}$-translocating P-type KDP-ATPase have a structure similar to that of $\mathbf{K}^{+}$channels? Biophys J 2000, 78:188-199.

12. Kremling A, Heermann R, Centler F, Jung K, Gilles ED: Analysis of two-component signal transduction by mathematical modeling using the KdpD/KdpE system of Escherichia coli . Biosystems 2004, 78(I-3):23-37.

13. Yu D, Ellis HM, Lee EC, Jenkins NA, Copeland NG, Court DL: An efficient recombination system for chromosome engineering in Escherichia coli . Proc Natl Acad Sci USA 2000, 97:5978-5983.

14. Wong QN, Ng VC, Lin MC, Kung HF, Chan D, Huang JD: Efficient and seamless DNA recombineering using a thymidylate synthase A selection system in Escherichia coli . Nucleic Acids Res 2005, 33:e59.

15. Warming S, Costantino N, Court DL, Jenkins NA, Copeland NG: Simple and highly efficient BAC recombineering using galK selection. Nucleic Acids Res 2005, 33:e36.

16. Yang XW, Model $\mathrm{P}$, Heintz N: Homologous recombination based modification in Escherichia coli and germline transmission in transgenic mice of a bacterial artificial chromosome. Nat Biotechnol 1997, I 5:859-865.

17. Gong S, Yang XW, Li C, Heintz N: Highly efficient modification of bacterial artificial chromosomes (BACs) using novel shuttle vectors containing the R6Kgamma origin of replication. Genome Res 2002, I2:1992-1998.
18. Herring CD, Glasner JD, Blattner FR: Gene replacement without selection: regulated suppression of amber mutations in Escherichia coli . Gene 2003, 31 I:153-163.

19. Posfai G, Kolisnychenko V, Bereczki Z, Blattner FR: Markerless gene replacement in Escherichia coli stimulated by a doublestrand break in the chromosome. Nucleic Acids Res 1999 , 27:4409-44I5.

20. Jamsai D, Orford M, Nefedov M, Fucharoen S, Williamson R, loannou PA: Targeted modification of a human beta-globin locus BAC clone using GET Recombination and an I-Scel counterselection cassette. Genomics 2003, 82:68-77.

21. Cox MM, Layton SL, Jiang T, Cole K, Hargis BM, Berghman LR, Bottje WG, Kwon YM: Scarless and site-directed mutagenesis in Salmonella enteritidis chromosome. BMC Biotechnol 2007, 7:59.

22. Muyrers JP, Zhang Y, Benes V, Testa G, Ansorge W, Stewart AF: Point mutation of bacterial artificial chromosomes by ET recombination. $E M B O \operatorname{Rep} 2000,1: 239-243$.

23. Solano C, Garcia B, Valle J, Berasain C, Ghigo JM, Gamazo C, Lasa I: Genetic analysis of Salmonella enteritidis biofilm formation: critical role of cellulose. Mol Microbiol 2002, 43:793-808.

24. Derbise A, Lesic B, Dacheux D, Ghigo JM, Carniel E: A rapid and simple method for inactivating chromosomal genes in Yersinia. FEMS Immunol Med Microbiol 2003, 38: I I3-1 16.

25. Beloin C, Deighan P, Doyle M, Dorman C): Shigella flexneri 2a strain 2457T expresses three members of the H-NS-like protein family: characterization of the Sfh protein. Mol Genet Genomics 2003, 270:66-77.

26. Mundy R, Petrovska L, Smollett K, Simpson N, Wilson RK, Yu J, Tu $X$, Rosenshine I, Clare S, Dougan G, Frankel G: Identification of a novel Citrobacter rodentium type III secreted protein, Espl, and roles of this and other secreted proteins in infection. Infect Immun 2004, 72:2288-2302.

27. Rossi MS, Paquelin A, Ghigo JM, Wandersman C: Haemophoremediated signal transduction across the bacterial cell envelope in Serratia marcescens : the inducer and the transported substrate are different molecules. Mol Microbiol 2003, 48: $|467-| 480$.

28. Sambrock J, Fritsch EF, Maniatis T: Molecular cloning: a laboratory manual. Cold Spring Harbor, N.Y.: Cold Spring Harbor Laboratory; 1989.

29. Epstein W, Kim BS: Potassium transport loci in Escherichia coli K-I 2. J Bacteriol I 97I, I 08:639-644.

30. Promega: Altered sites II in vitro mutagenesis system. Technical Manual 1994

31. Blattner FR, Plunkett G, Bloch CA, Perna NT, Burland V, Riley M, Collado-Vides J, Glasner JD, Rode CK, Mayhew GF, Gregor J, Davis NW, Kirkpatrick HA, Goeden MA, Rose DJ, Mau B, Shao Y: The complete genome sequence of Escherichia coli K-I2. Science 1997. 277:1453-1474.
Publish with Bio Med Central and every scientist can read your work free of charge

"BioMed Central will be the most significant development for disseminating the results of biomedical research in our lifetime. "

Sir Paul Nurse, Cancer Research UK

Your research papers will be:

- available free of charge to the entire biomedical community

- peer reviewed and published immediately upon acceptance

- cited in PubMed and archived on PubMed Central

- yours - you keep the copyright
BioMedcentral 